\title{
Suicidal ideation among Lebanese adults: scale validation and correlates
}

\author{
Maha Zakhour ${ }^{1 \dagger}$, Chadia Haddad ${ }^{2 \dagger}$, Hala Sacre ${ }^{3}$, Kassandra Fares ${ }^{4}$, Marwan Akel ${ }^{3,5}$, Sahar Obeid ${ }^{3,4,6^{*} \dagger}$, \\ Pascale Salameh ${ }^{3,7,8+}$ and Souheil Hallit ${ }^{3,9^{*}+}$ (i)
}

\begin{abstract}
Background: According to the World Health Organization (WHO) figures in 2015, the number of people attempting suicide worldwide per year exceeds 800,000 individuals. The majority of completed suicides (78\%) occur in low- and middle-income countries. Therefore, this study aimed to validate the suicidal ideation subscale of the Columbia-Suicide Severity Rating Scale and evaluate risk factors (emotional intelligence, alexithymia, anxiety, depression, and stress) related to suicidal ideation among the Lebanese adult population.
\end{abstract}

Methods: A structured cross-sectional survey was carried out between November 2017 and March 2018, enrolling a proportionate random sample of 789 community-dwelling participants from all the Lebanese regions. A correlation analysis between the C-SSRS and anxiety and depression assessed the convergent validity of the scale. An exploratory and a confirmatory factor analysis validated its construct. Cronbach's alpha was used to assess internal consistency reliability. Multiple linear regression was performed using the suicidal ideation score as the dependent variable. All variables were included in the multivariable model.

Results: The C-SSRS scale converged over a solution of one factor; the proportion of explained variance was 0.797. The Cronbach's alpha value was good (0.797). The convergent validity was tested with depression and anxiety scales. The results showed a moderate positive correlation between the suicide ideation score and depression (rho $=0.507, p<0.001)$ and anxiety $(r h o=0.402, p<0.001)$. The multivariable analysis showed that higher depression (Unstandardized Beta, $B=0.035, p<0.001)$, higher anxiety $(B=0.015, p=0.008)$, and higher alcohol dependence $(B=0.024, p<0.001)$ were significantly linked to higher suicidal ideation score. However, higher self-esteem $(B=-$ $0.041, p=0.006)$ was significantly associated with lower suicidal ideation scores.

Conclusion: Our findings suggest that the Arabic version of the C-SSRS subscale could serve as an appropriate assessment tool for suicidal ideation. This paper also gave insights into factors correlated with higher suicidal ideation scores, such as depression, anxiety, and alcohol dependence. Further studies are necessary to confirm our findings and implement suicide prevention programs.

Keywords: Suicidal ideation, Depression, Anxiety, Alexithymia, Emotional intelligence

\footnotetext{
*Correspondence: saharobeid23@hotmail.com; souheilhallit@hotmail.com

${ }^{+}$Maha Zakhour and Chadia Haddad are first co-authors.

†Sahar Obeid, Pascale Salameh and Souheil Hallit are last co-authors.

${ }^{3}$ INSPECT-LB: National Institute of Public Health, Clinical Epidemiology and

Toxicology, Beirut, Lebanon

Full list of author information is available at the end of the article
}

(C) The Author(s). 2021 Open Access This article is licensed under a Creative Commons Attribution 4.0 International License, which permits use, sharing, adaptation, distribution and reproduction in any medium or format, as long as you give appropriate credit to the original author(s) and the source, provide a link to the Creative Commons licence, and indicate if changes were made. The images or other third party material in this article are included in the article's Creative Commons licence, unless indicated otherwise in a credit line to the material. If material is not included in the article's Creative Commons licence and your intended use is not permitted by statutory regulation or exceeds the permitted use, you will need to obtain permission directly from the copyright holder. To view a copy of this licence, visit http://creativecommons.org/licenses/by/4.0/ The Creative Commons Public Domain Dedication waiver (http://creativecommons.org/publicdomain/zero/1.0/) applies to the data made available in this article, unless otherwise stated in a credit line to the data. 


\section{Background}

Suicide is a considerable health problem worldwide; it is one of the top fifteen causes of death across the global population and the second leading cause in young adults $[1,2]$. According to the World Health Organization (WHO) figures in 2015, the number of people attempting suicide worldwide per year exceeds 800,000 individuals [3]. In the United States, suicide is the 10th leading cause of death for all ages; the suicidal rate increased by 35\% from 1999 through 2018, for both males and females [4]. In 2017, 1.4\% of global deaths were from suicide [3]. The majority of completed suicides (78\%) occur in low- and middle-income countries.

Studies have identified several acute and chronic risk factors for suicide, most notably suicidal ideation and attempts and other indicators of mental health, substance use, and psychosocial resources. Suicide thoughts and attempts are predictors of suicide deaths $[3,5,6]$. Suicidal ideation refers to any intention to die, kill self, or plan to end life $[7,8]$. Women are 3 to 4 times more likely to attempt suicide, while men are more likely to commit suicide [9]. Overall, for every 20 suicidal attempts, one complete suicide is realized [10]. The acute state, known as the suicide crisis syndrome, is identified as the short term suicidal risk, while chronic risk factors are referred to as long term suicidal risk [11]. Chronic risk factors include mental illness, suicidal ideation, previous suicide attempts, severe hopelessness, a history of childhood maltreatment, insecure attachment, chronic substance use, impulsivity, lack of social support, and perfectionism $[11,12]$. Acute risk factors for suicide include sleep disturbances, loss of concentration and interest, severe anxiety, irritability, anhedonia, and social isolation [13]. Depression is the most prevalent psychiatric disorder in suicide attempts $[14,15]$. It plays a central role in the transition from suicidal ideations to suicide attempts [16]. Depressed persons lack energy, motivation, and initiative; they also have persistent fatigue and sadness. Anxiety was not shown to be directly related to suicidal attempts: anxious individuals may refrain from having suicidal thoughts because they fear harm [17]. However, the avoidance behaviors characterizing anxiety disorders lead to functional disability that may increase vulnerability to suicide [18]. Also, social anxiety was seen as an indicator of suicidal ideation, as addressing the feeling of loneliness and low perception of social support may increase suicidal ideation and attempts [19]. Panic attacks were also identified as a risk factor for attempted suicide among depressed persons with or without suicidal ideation [20].

Researchers have been accumulating evidence that some stressful conditions may increase the risk for suicidal ideation and attempts [21-23], such as an overloading persisting situation, constant stress, and negative life experiences or incidents, leading to mental health disorders and suicidal ideation [23]. Low self-esteem was also linked to increased suicidal tendencies and tentative [24-26]. A constant negative view of oneself may include seeing oneself as worthless, the future as hopeless, and life as not worth living [27]. The consumption of alcoholic beverages has also been associated with suicidal thoughts and attempts [28]. Drinking alcohol by itself cannot lead to suicide; however, the consequence of alcohol addiction could include destructive behaviors such as losing a job, domestic and work problems, violent or criminal acts, and social withdrawal [29]. These factors can lead to depression, and subsequently, suicidal thoughts and actions [29]. Alexithymia, described as the inability to identify emotions or express them [30], has also been linked to suicide ideation [31]. People with alexithymia may develop emotional dysregulation and confusing information, leading to feelings of helplessness [32]. Individuals with poor emotional clarity have difficulty regulating their emotions; they use maladaptive coping mechanisms, such as social isolation, which contribute to suicide ideation and behavior because of limited ways of coping with the feelings they have [31]. Oppositely, the role of emotional intelligence (EI) in promoting positive emotions and well-being is crucial [33]. People with high EI people are likely to make and keep tight connections, express emotions and feelings, and improve their subjective well-being [34]. Thus, EI could be a protective factor against suicide [35].

In Lebanon, suicide rates have increased during the last years. Police data indicate that 100 suicides were recorded in the first 5 months of this year, compared to 147 suicides in all of 2017 and 200 suicides in all of 2018 [36]. Indeed, mental health conditions are common in the Lebanese population that has high mental health problems, similar to European countries like France, Italy, Belgium, and others [37]. A study among 2857 Lebanese adults has found that the lifetime prevalence of mental disorders was $25.8 \%$, with $10.5 \%$ of the studied sample having more than one [38]. The projecting lifetime risk was approximately $32.9 \%$, meeting the criteria for one or more of the DSM-IV disorders [38]. Different stressful factors increase suicidal ideations among the Lebanese population, such as the unstable political situation resulting from a 20-year civil war [39], environmental problems (chronic power shortage, lack of clean water, and waste mismanagement) [39], and the economic hardship translating into lack of vacancies and increased unemployment due to the competition with the Syrian refugees [40]. A study suggested that one of the most important reasons for the rising suicide rates could be Lebanon's economic decline that worsened almost 2 years ago [36]. Another research recently explored suicidal ideation among Lebanese adolescents and found 
that $28.9 \%$ of teenagers had suicidal thoughts [41]; previous studies had shown that the prevalence of suicidal ideation among Lebanese adults was $12 \%$ [42, 43]. In Lebanon, the risk factors for suicide ideation identified among adolescents [44] included gender (females more at risk), depression, sadness, loneliness, alcohol and drug abuse, bullying, and several other factors [45].

Assessing suicidal thoughts and behaviors is essential to complement clinical evaluation and prevent suicide [46]. Several instruments have been used for this purpose [47], among which the Columbia-Suicide Severity Rating Scale or C-SSRS, designed to measure the severity of suicide ideation and type of suicidal behavior [48]. It has been translated into 125 languages, including the Lebanese Arabic language. The initial version of the CSSRS was assessed in three multisite studies with adolescents and adults: the tool demonstrated a high internal consistency $(\alpha=0.73$ to 0.95$)$, a strong integration $(r=$ 0.80 ), and divergence, in addition to high sensitivity and specificity for suicidal behavior compared with other suicidal and behavior scales [48].

In Lebanon, most studies focused on adolescents, with the C-SSRS showing adequate reliability $(\alpha=0.966)$ and good convergent validity with psychological scales [41]. However, it is not known whether this tool is valid and reliable for assessing suicidal ideation among adults. Therefore, this study aimed to validate the suicidal ideation subscale of the Columbia-Suicide Severity Rating Scale and evaluate risk factors (emotional intelligence, alexithymia, anxiety, depression, and stress) related to suicidal ideation among the Lebanese adult population.

\section{Methods}

\section{Sampling and data collection}

A structured cross-sectional survey was carried out between November 2017 and March 2018, enrolling a proportionate random sample of 789 community-dwelling participants from all the Lebanese regions. Out of 1000 questionnaires distributed, $789(78.9 \%)$ were completed and collected back; 211 (21.1\%) of the contacted people declined to participate.

Lebanon is divided into five Governorates (Mohafazat), Mount Lebanon, Beirut, North, Beqaa, and South, in turn, divided into Districts (Caza) from which two villages were randomly selected from the list provided by the Lebanese Central Agency of Statistics.

In each village, the questionnaires were distributed to the randomly selected household. All individuals above 18 were eligible. A clinical psychologist assessed participants' cognitive abilities, and those deemed unable to respond and understand the questions were excluded from the study. People who agreed to participate were asked to fill out the survey form via a face-to-face interview.
Those who did not know how to read or write were offered assistance.

Participants were briefed on the aims and methods of the study before enrolling. They had the right to accept or refuse to participate. Those who agreed signed written informed consent and received no financial compensation for their participation. Their anonymity was guaranteed during the data collection process. The same methodology was used in previous papers [49-52].

\section{Minimal sample size calculation}

According to Comrey and Lee, at least ten observations per item are necessary to carry out an exploratory factor analysis [53]. Therefore, a minimum sample of 50 patients was required in this study since the suicidal ideation part of the C-SSRS questionnaire comprises of five items.

\section{Procedure}

A study-independent clinical psychologist interviewed the participants, using a paper-pen method to collect the resulting data. Questions were written and asked in Arabic, the native language in Lebanon.

\section{Translation procedure}

All scales were forward and backward translated, except for the Hamilton depression rating scale and the Hamilton anxiety scale, already validated in Lebanon [54, 55]. One bilingual translator translated the scales from English into Arabic. Another translator performed the back-translation from Arabic into English. Discrepancies were resolved by consensus.

\section{Questionnaire}

The first section assessed sociodemographic and other characteristics of the participants, such as age, gender, and level of education. It also gathered information about their monthly income, classified into no income, low ( $<1000$ US dollars), intermediate (between 1000 and 2000 US dollars), and high ( $>2000$ US dollars). The second part included the various scales used in this survey.

\section{The Columbia-suicide severity rating scale (C-SSRS)}

The Columbia Suicide Severity Rating Scale (C-SSRS) is a 10-item dichotomous scale developed by researchers from the universities of Columbia, Pennsylvania, and Pittsburgh to evaluate suicidal ideation (5 questions) and behavior (5 questions) [48]. This study used the five questions about suicidal ideation: "wish to be dead", "suicidal thoughts", "suicidal thoughts with a method", "suicidal intent", and "suicidal intent with a specific plan". A score evaluating suicidal ideation in the past week was created by summing the responses to the five items, where a score of "0" indicates no suicidal ideation. 
An answer of yes to any of the five questions signs the presence of suicidal ideation [56], with higher scores indicating more suicidal ideation $\left(\alpha_{\text {Cronbach }}=0.796\right)$. The possible range for the suicidal ideation subscale was $0-5$.

\section{The alcohol use disorders identification test (AUDIT)}

The AUDIT is a 10-item scale that measures alcohol consumption, drinking behaviors, and problems related to alcohol in the past year [57]. The assessment period was done during the last year. Examples of items: "How often do you have a drink containing alcohol?", "How many drinks containing alcohol do you have on a typical day when you are drinking?". Items 1 to 8 are graded on a scale from 0 (never) to 4 (daily or almost daily) [57]. Questions 9 and 10 have only three possible responses and are scored 0, 2, and 4 [57]. The total AUDIT score was used and ranged from 0 to 40. Scores of eight or above indicate alcohol use disorder $\left(\alpha_{\text {Cronbach }}=0.885\right)$ [57].

\section{The Toronto alexithymia scale (TAS-20)}

This 20-item tool evaluates alexithymia over the last month. Answers are rated on a 5-point Likert scale from 1 (strongly disagree) to 5 (strongly agree) [58]. Examples of items: "I am often confused about what emotion I am feeling", "It is difficult for me to find the right words for my feelings", "I prefer to analyze problems rather than just describe them". The total TAS-20 score was used and ranged between 20 and 100, with higher scores indicating higher alexithymia [58] $\left(\alpha_{\text {Cronbach }}=0.778\right)$.

\section{The Rosenberg self-esteem scale (RSES)}

The RSES consists of 10 items that measure self-esteem over the last month [59]. Examples of items: "On the whole, I am satisfied with myself", "At times I think I am no good at all", "I feel that I have a number of good qualities". All answers are graded on a 4-point Likert scale from 1 (strongly disagree) to 4 (strongly agree). The total score was used and ranged from 10 to 40. Higher scores indicate greater self-esteem $\left(\alpha_{\text {Cronbach }}=\right.$ 0.733).

\section{Hamilton depression rating scale (HDRS)}

The HDRS, validated in Lebanon, is used to assess depression experienced over the past week [54]. It consists of 21 items, but the scoring is based on the first 17 only. Of these 17, eight are rated on a 5-point scale from 0 (not present) to 4 (severe) [60], and nine from 0 to 2 . The total score is calculated by summing the responses to the 17 questions. Examples of items: "depressed mood", "feelings of guilt", "suicide". The total HDRS score was used and ranged from 0 to a maximum of 52 points. Higher scores indicate higher depression [60] $\left(\alpha_{\text {Cronbach }}=0.890\right)$.

\section{Hamilton anxiety scale (HAM-A)}

This tool, previously validated in Lebanon, is used to evaluate anxiety over the past week [55]. Examples of items: "Anxious mood", "Tension", "Fears". Each question is rated on a 5 -point scale from 0 (not present) to 4 (severe), with a total score ranging between 0 and 56 [61]. Higher scores indicate higher anxiety $\left(\alpha_{\text {Cronbach }}=\right.$ 0.898).

\section{The perceived stress scale (PSS)}

The PSS consists of 10 items measuring the perception of stress during the last month. Examples of items: "In the last month, how often have you been upset because of something that happened unexpectedly?", "In the last month, how often have you felt that you were unable to control the important things in your life?", "In the last month, how often have you felt nervous and stressed?". Responses are graded on a scale from 0 (never) to 4 (very often) [62]. The total score was used and ranged from 0 to 40, with higher scores indicating higher perceived stress $\left(\alpha_{\text {Cronbach }}=0.667\right)$.

\section{Liebowitz social anxiety scale (LSAS)}

The LSAS is a 24-item self-report scale that measures social anxiety disorder over the past week [63]. Questions are divided into two subcategories evaluating fear and avoidance. Examples of items: "Participating in a small group activity", "Drinking with others", "Acting, performing, or speaking in front of an audience". Questions are rated on a scale from 0 (none for fear, or never for avoidance) to 3 (severe for fear and usually for avoidance). The total score calculated by summing the answers to the two subcategories varies between 0 and 144. A higher score indicates very severe social phobia. The Cronbach's alpha values for the total score, avoidance, and fear scores were 0.954, 0.953, and 0.945, respectively.

\section{The quick emotional intelligence self-assessment}

This scale consists of 40 items divided into four subscales of ten questions: emotional awareness, emotional management, social-emotional awareness, and relationship management. Items are scored on a Likert scale from 0 (never) to 4 (always). Examples of questions: "My feelings are clear to me at any given moment", "I accept responsibility for my reactions", "I consider the impact of my decisions on other people", "I am able to show affection". The total score was used and calculated by summing all items of the four subscales and ranges from 0 to 160 stress $\left(\alpha_{\text {Cronbach }}=0.958\right)[64]$.

\section{Statistical analysis}

Data were analyzed using SPSS software version 25. A descriptive analysis was carried out using numbers and 
percentages for categorical variables and means and standard deviations for continuous measurements. Factor analysis and confirmatory factor analysis validated the construct of the C-SSRS scale. Factor analysis using the Principal Component Analysis (PCA) was performed via the "FACTOR" procedure. The Kaiser-Meyer-Olkin sampling adequacy measure and Bartlett's sphericity test were appropriate. All factors retained had an Eigenvalue over 1. A promax rotation was performed because the extracted factors were correlated. This procedure was followed by a Confirmatory Factor Analysis (CFA), which examined the fit of the factor model of the suicidal ideation score. The following goodness-of-fit indicators were reported: the chi-square to $\mathrm{df}$ ratio $(\mathrm{x} 2 / \mathrm{df})$, the Root Mean Square Error of Approximation (RMSE A), the Goodness-of-fit statistic (GFI), and the adjusted goodness-of-fit statistic (AGFI). The $\chi^{2} / \mathrm{df}$ having a low sensitivity to sample size, it can be used as an index of goodness of fit (with recommended values ranging between 2 and 5). Also, RMSEA values of less than 0.05 are indicative of a close fit, and values lower than 0.11 indicate an acceptable fit. As for the GFI and AGFI, values of 0.90 or greater indicate well-fitted models [65]. The confirmatory factor analysis was done using the STATISTICA software version 12.

Cronbach's alpha test assessed the reliability of the suicidal ideation score. The cut-offs for reliability were as follow: poor (less than 0.6), moderate (between 0.6 and 0.7 ), good (between 0.7 and 0.8 ), very good (between 0.8 to 0.9), excellent (higher than 0.9) [66]. A Spearman correlation between C-SSRS and the other measures was done to establish convergent validity. The Correlation coefficient values of $|0.1-0.3|,|0.3-0.7|$, and > | 0.7 | indicate weak, moderate, and strong correlations, respectively [67]. Linear regression was performed, having the dependent variable as the suicidal ideation score. All variables were included in the multivariable model.

Furthermore, since the suicidal ideation score was not normally distributed (as verified by the Shapiro Wilk test), non-parametric tests were used (Kruskal-Wallis for comparing three groups or more and Mann-Whitney tests for comparing two groups). Multiple linear regression was performed using the suicidal ideation score as the dependent variable. All variables were included in the multivariable model. In all cases, a value of $\mathrm{p}<(0.05)$ was considered statistically significant.

\section{Results}

Table 1 presents the sociodemographic features of the participants. The mean age was $30.30 \pm 12.52$ years, with $54.8 \%$ males. The majority $(70.9 \%)$ had a university level of education, $63.1 \%$ were single, and $50.7 \%$ earned less than 1000 US dollars per month.
Table 1 Sociodemographic characteristics of the sample population

\begin{tabular}{ll}
\hline & Frequency (\%) \\
\hline Gender & $423(54.8 \%)$ \\
Male & $349(45.2 \%)$ \\
Female & \\
Education level & $12(1.6 \%)$ \\
Illiterate (no schooling/less than primary education) & $39(5.3 \%)$ \\
Primary & $52(7.0 \%)$ \\
Complementary & $113(15.2 \%)$ \\
Secondary & $526(70.9 \%)$ \\
University & \\
Socioeconomic status & $376(50.7 \%)$ \\
$<1000 \$$ & $260(35.1 \%)$ \\
1000-2000 \$ & $105(14.2 \%)$ \\
$>$ 2000 \$ & \\
Marital status & $488(63.1 \%)$ \\
Single & $236(30.5 \%)$ \\
Married & $19(2.5 \%)$ \\
Widowed & $30(3.9 \%)$ \\
Divorced & Mean \pm SD \\
Age (in years) & $30.30 \pm 12.52$ \\
\hline
\end{tabular}

\section{Description of the used scales}

Of the total sample, 228 (28.9\%) participants had suicidal ideations, with a mean suicidal ideation score of $0.57 \pm$ $1.16,19.8 \%$ of participants wished to be dead, $9.6 \%$ had suicidal thoughts, $13.8 \%$ suicidal thoughts with a method, $25.5 \%$ suicidal intent, and $23.3 \%$ suicidal intent with a specific plan (Table 2). The mean, SD, and the range of the scales used are presented in Table 3.

\section{Construct validity}

A factor analysis using the promax rotated matrix for the C-SSRS was run over the whole sample. The results showed that all variables could be extracted from the questions asked. The C-SSRS scale converged over a solution of one factor (Eigenvalue $>\mid 1$ ), the proportion of explained variance was $0.797(\mathrm{KMO}=0.899$; Bartlett's test of sphericity $p<0.001$ ) (Table 4 ).

The confirmatory factor analysis showed that the Maximum Likelihood Chi-Square $=7.55$ and Degrees of Free$\mathrm{dom}=5$, resulting in a $X 2 / \mathrm{df}=1.51$. The Steiger-Lind RMSEA was equal to 0.052 , while the Joreskog GFI and AGFI were 0.986 and 0.957 , respectively.

\section{Convergent validity}

The convergent validity with the C-SSRS was tested with the mental scales used. The results showed a moderate 
Table 2 Description of the suicidal ideation scale

\begin{tabular}{|c|c|}
\hline & Frequency (\%) \\
\hline \multicolumn{2}{|c|}{ Suicide ideation (Most severe in the past week) } \\
\hline \multicolumn{2}{|l|}{ 1. Wish to be dead } \\
\hline Yes & $144(19.8 \%)$ \\
\hline No & $582(80.2 \%)$ \\
\hline \multicolumn{2}{|l|}{ 2. Suicidal thoughts } \\
\hline Yes & $71(9.6 \%)$ \\
\hline No & $671(90.4 \%)$ \\
\hline \multicolumn{2}{|c|}{$\begin{array}{l}\text { 3. Suicidal thoughts with a method (but without specific plan or inten } \\
\text { to act) }\end{array}$} \\
\hline Yes & $66(13.8 \%)$ \\
\hline No & $414(86.2 \%)$ \\
\hline \multicolumn{2}{|l|}{ 4. Suicidal intent (without specific plan) } \\
\hline Yes & $82(25.5 \%)$ \\
\hline No & $239(74.5 \%)$ \\
\hline \multicolumn{2}{|l|}{ 5. Suicidal intent with a specific plan } \\
\hline Yes & $66(23.3 \%)$ \\
\hline No & $217(76.7 \%)$ \\
\hline \multicolumn{2}{|l|}{ Suicidal ideation score } \\
\hline Presence of suicidal ideation & $228(28.9 \%)$ \\
\hline Absence of suicidal ideation is present & $561(74.8 \%)$ \\
\hline
\end{tabular}

positive correlation between the suicide ideation score and the HDRS (rho $=0.507, p<0.001$ ) and the HAM-A (rho $=0.402, \mathrm{p}<0.001)$. Moreover, a moderate positive correlation was found between suicide ideation score and alcohol dependence (rho $=0.393, p<0.001)$, while a moderate negative association was found between suicide ideation score and emotional intelligence $(\mathrm{rho}=-$ $0.318, p<0.001)$. A weak positive correlation was found between suicide ideation score and alexithymia $(\mathrm{rho}=$ $0.137, p<0.001$ ), perceived stress ( $\mathrm{rho}=0.143, \mathrm{p}<0.001$ ), and social anxiety (rho $=0.121, p=0.002$ ). However, a weak negative correlation was found between suicide ideation score and self-esteem score (rho $=-0.271, p<$ 0.001) (Table 5).

\section{Bivariate analysis}

The results of the bivariate analysis are summarized in Table 6. The mean of the C-SSRS scale was higher in male participants than in females $(0.69$ vs. $0.40, p<$ 0.001). It was also higher among widowed than single participants $(1.78$ vs. $0.50, \mathrm{p}<0.001)$. No significant correlation was found between suicide ideation score and age (rho $=-0.05, p=0.885)$.

\section{Multivariable analysis}

A linear regression taking the C-SSRS scale as the dependent variable showed that higher depression (Unstandardized Beta, $\mathrm{B}=0.035, \mathrm{p}<0.001$ ), higher anxiety $(\mathrm{B}=0.015, p=0.008)$, and higher alcohol dependence $(B=0.024, p<0.001)$ were significantly linked to higher suicidal ideation score. However, higher self-esteem $(\mathrm{B}=-0.041, p=0.006)$ was significantly associated with lower suicidal ideation scores (Table 7).

\section{Discussion}

The current study determined the psychometric characteristics of the C-SSRS translated into Arabic and examined the risk factors associated with suicide ideation among Lebanese adults. This scale exhibited adequate construct validity and internal consistency. The results also showed that depression, anxiety, and alcohol dependence were positively associated with suicidal ideation.

\section{Validation of the C-SSRS}

The results showed that the Arabic version of the CSSRS has satisfactory psychometric properties with adequate internal consistency, which offers initial evidence that it could be used in Lebanon to screen for suicidal ideation. The construct validity of the C-SSRS scale was

Table 3 Description of the used scales

\begin{tabular}{|c|c|c|c|c|c|c|c|}
\hline & Mean & SD & Median & Interquartile range (IQR) & Minimum & Maximum & Range \\
\hline Suicidal ideation score & 0.57 & 1.16 & 0.001 & 1.00 & 0 & 5 & $0-5$ \\
\hline Audit score & 10.36 & 8.21 & 8.00 & 14.00 & 0 & 39 & $0-40$ \\
\hline TAS score & 52.11 & 10.43 & 52.00 & 14.00 & 20 & 91 & $20-100$ \\
\hline HAM-D score & 12.67 & 10.50 & 11.00 & 16.00 & 0 & 44 & $0-52$ \\
\hline Self-esteem score & 24.67 & 4.63 & 25.00 & 3.00 & 10 & 37 & $10-40$ \\
\hline HAM-A score & 14.19 & 10.10 & 15.00 & 16.50 & 0 & 47 & $0-56$ \\
\hline PSC score & 18.50 & 5.92 & 19.00 & 7.00 & 0 & 37 & $0-40$ \\
\hline LSAS & 39.71 & 2.91 & 37.00 & 30.00 & 0 & 128 & $0-144$ \\
\hline El & 81.93 & 29.35 & 81.00 & 37.00 & 0 & 160 & $0-160$ \\
\hline
\end{tabular}

TAS Toronto Alexithymia Scale, HAMD Hamilton depression rating scale (HDRS), HAMA Hamilton anxiety scale, PSC Perceived Stress Scale, LSAS Liebowitz Social Anxiety Scale, El Emotional intelligence total score 
Table 4 Factor analysis of the Columbia - suicide severity rating scale items using the promax rotation

\begin{tabular}{llll}
\hline & & Factor 1 & Communality \\
\hline Item 1 & Wish to be Dead & 0.867 & 0.751 \\
Item 2 & Non-Specific Active Suicidal Thoughts & 0.921 & 0.848 \\
Item 3 & Active Suicidal Ideation with Any Methods (Not Plan) without Intent to Act & 0.900 & 0.811 \\
Item 4 & Active Suicidal Ideation with Some Intent to Act, without Specific Plan & 0.919 & 0.844 \\
Item 5 & Active Suicidal Ideation with Specific Plan and Intent & 0.854 \\
Cronbach's alpha & & 0.796 & 0.730 \\
Proportion of variance explained & 0.797 \\
\hline
\end{tabular}

adequate since items converged over one factor. The validated Spanish version of the C-SSRS had an adequate internal consistency of 0.87 , and the factor loading of the scale yielded two items factors for suicidal thoughts and behavior, respectively [68]. The first factor included ten items, consistent with the concept of suicide ideation [68]. The concurrent validity of the Spanish scale has found a positive relationship with depression [68], similar to our results. The Cronbach's alpha value for the CSSRS scale was good equal to 0.797, which is consistent with a study that found Cronbach's alpha values ranging between 0.73 and 0.93, indicating good internal consistency for the suicide ideation subscale of the CSSRS [48]. The wide variations across studies are due to differences in the characteristics of the sample, the population surveyed, and the scale used. Our findings revealed that the means of items of the suicidal ideation subscale ranged from 0.09 to 0.25 , with the highest reported frequency for item 4 (suicidal intent without a specific plan), consistent with the results of the Spanish study, showing means ranging from 0.11 to 0.15 [68].

Our results revealed a moderate convergent validity between the suicidal ideation score and depression and anxiety. A previous study had demonstrated a good convergent validity between the C-SSRS and items on the Beck Depression Inventory (BDI) and the MontgomeryÅsberg Depression Rating Scale (MADRS) [48]; this discrepancy in results could be due to the difference in the scales used to assess depression and anxiety. Another explanation would be that both the BDI and MADRS include questions about suicidal ideation, leading to a better correlation with the C-SSRS. Moreover, depression and anxiety were related to suicidal ideation score, consistent with previous findings showing that both are correlated with suicidal ideation and increased thoughts of suicide [69-73].

\section{Suicide ideation correlates}

Our results showed that the prevalence of suicidal ideation among Lebanese adults was $28.9 \%$, in line with those of a previous study among Lebanese adolescents [41] but higher than the findings of other studies [74, 75]. Indeed, the overall prevalence of suicidal ideation in 12 Muslim-majority countries was $22 \%$, with $12 \%$ in the 87 Lebanese participants [42]. It is noteworthy that all religions prohibit suicide and that the majority of people

Table 5 Correlation matrix among the scales used

\begin{tabular}{|c|c|c|c|c|c|c|c|c|c|}
\hline & $\begin{array}{l}\text { Suicide ideation } \\
\text { score }\end{array}$ & $\begin{array}{l}\text { Audit } \\
\text { score }\end{array}$ & $\begin{array}{l}\text { TAS } \\
\text { score }\end{array}$ & $\begin{array}{l}\text { HAM-D } \\
\text { score }\end{array}$ & $\begin{array}{l}\text { Self-esteem } \\
\text { score }\end{array}$ & $\begin{array}{l}\text { HAM-A } \\
\text { score }\end{array}$ & $\begin{array}{l}\text { PSC } \\
\text { score }\end{array}$ & LSAS & El \\
\hline $\begin{array}{l}\text { Suicide ideation } \\
\text { score }\end{array}$ & - & $0.393^{*}$ & $0.137^{*}$ & $0.507^{*}$ & $-0.271^{*}$ & $0.402^{*}$ & $0.143^{*}$ & $0.121 *$ & $-0.318^{*}$ \\
\hline Audit score & $0.393^{*}$ & - & $0.274^{*}$ & $0.509 *$ & $-0.249^{*}$ & $0.411 *$ & $0.165^{*}$ & $0.165^{*}$ & $\overline{0.312^{*}}$ \\
\hline TAS score & $0.137^{*}$ & $0.274^{*}$ & - & $0.284^{*}$ & $-0.307^{*}$ & $0.349^{*}$ & $0.388^{*}$ & $0.138^{*}$ & $-0.122 *$ \\
\hline HAM-D score & $0.507^{*}$ & $0.509^{*}$ & $0.284^{*}$ & - & $-0.385^{*}$ & $0.668^{*}$ & $0.250^{*}$ & $0.297^{*}$ & $-0.394 *$ \\
\hline Self-esteem score & $-0.271^{*}$ & $-0.249 *$ & $-0.307^{*}$ & $-0.385^{*}$ & - & $-0.375^{*}$ & $-0.240^{*}$ & $\overline{0.262^{*}}$ & $0.426^{*}$ \\
\hline HAM-A score & $0.402^{*}$ & $0.411^{*}$ & $0.349^{*}$ & $0.668^{*}$ & $-0.375^{*}$ & - & $0.342^{*}$ & $0.277^{*}$ & $-0.346 *$ \\
\hline PSC score & $0.143^{*}$ & $0.165^{*}$ & $0.388^{*}$ & $0.250^{*}$ & $-0.240^{*}$ & $0.342^{*}$ & - & $0.109 *$ & $-0.135^{*}$ \\
\hline LSAS & $0.121 *$ & $0.165^{*}$ & $0.138^{*}$ & $0.297^{*}$ & $-0.262^{*}$ & $0.277^{*}$ & $0.109^{*}$ & - & $-0.248^{*}$ \\
\hline El & $-0.318^{*}$ & $-0.312^{*}$ & $0.122^{*}$ & $-0.394^{*}$ & $0.426^{*}$ & $-0.346^{*}$ & $-0.135^{*}$ & $-0.248^{*}$ & - \\
\hline
\end{tabular}

TAS Toronto Alexithymia Scale, HAMD Hamilton depression rating scale (HDRS), HAMA Hamilton anxiety scale, PSC Perceived Stress Scale, LSAS Liebowitz Social Anxiety Scale, El Emotional Intelligence total score

Values marked in bold are significant. * $p$ - value less than 0.01 
Table 6 Bivariate analysis of the factors associated with the CSSRS scale

\begin{tabular}{|c|c|c|}
\hline & C-SSRS scale & $p$-value \\
\hline & Mean \pm SD & \\
\hline \multicolumn{3}{|l|}{ Gender } \\
\hline Male & $0.69 \pm 1.33$ & $<0.001$ \\
\hline Female & $0.40 \pm 0.88$ & \\
\hline \multicolumn{3}{|l|}{ Marital status } \\
\hline Single & $0.50 \pm 1.12$ & $<0.001$ \\
\hline Married & $0.51 \pm 1.04$ & \\
\hline Widowed & $1.78 \pm 1.61$ & \\
\hline Divorced & $0.72 \pm 1.30$ & \\
\hline \multicolumn{3}{|c|}{ Socioeconomic status } \\
\hline$<1000 \$$ & $0.50 \pm 1.12$ & 0.171 \\
\hline $1000-2000 \$$ & $0.58 \pm 1.19$ & \\
\hline$>2000 \$$ & $0.75 \pm 1.23$ & \\
\hline \multicolumn{3}{|l|}{ Education level } \\
\hline Illiterate & $0.75 \pm 1.54$ & 0.707 \\
\hline Primary & $0.71 \pm 1.27$ & \\
\hline Complementary & $0.62 \pm 1.15$ & \\
\hline Secondary & $0.58 \pm 1.27$ & \\
\hline \multirow[t]{2}{*}{ University } & $0.50 \pm 1.09$ & \\
\hline & Correlation coefficient & $p$-value \\
\hline Age & -0.05 & 0.885 \\
\hline
\end{tabular}

Numbers in bold indicate significant $p$-values in Middle Eastern countries are practicing believers, which makes suicide a taboo in this part of the world, leading to a failure in collecting data about suicide and decreasing the prevalence of suicidal ideation and attempts $[42,74,75]$. The low number of participants in this study can explain the discrepancy with our results. However, further studies are needed to assess the reasons for these differences, including the nature of the sample.

Our results also showed that depression is highly correlated to suicidal ideation compared to the other variables examined, followed by anxiety. These findings are consistent with those of a previous study conducted among Tehran university students, showing that depression was the first contributor to suicidal ideation followed by anxiety; mental health, resiliency, and daily stress were respectively the other contributors [76]. Depressive symptoms are predictors of suicidal ideation in $94 \%$ of cases [76, 77]. Suicide is strongly related to mental disorders, such as depression, and other factors like anxiety are contributors [5]. Most of the people who committed suicide had mental disorders, among which depression [78]. This strong relationship between suicide and depression is not yet explored, and more studies are needed to clarify the characteristics of depression and its effects on suicide.

Our results showed that higher alcohol dependence was significantly associated with more suicidal ideation, in agreement with those of previous studies showing that alcohol abuse increases suicidal ideation, causes

Table 7 Multivariable analysis

\begin{tabular}{llllll}
\hline Model 1: Linear regression taking the C-SSRS scale as dependent variable and the scales as independent variables. \\
\hline & $\begin{array}{l}\text { Unstandardized } \\
\text { Beta }\end{array}$ & $\begin{array}{l}\text { Standardized } \\
\text { Beta }\end{array}$ & $\boldsymbol{p}$-value & \multicolumn{2}{c}{ Confidence interval } \\
\cline { 4 - 6 } & -0.115 & -0.051 & 0.170 & -0.278 & Upper Bound \\
\hline Gender (Male* vs Female) & -0.017 & -0.007 & 0.875 & -0.229 & 0.049 \\
Marital status (Single* vs Married) & 0.058 & 0.024 & 0.535 & -0.126 & 0.243 \\
Intermediate monthly income & 0.044 & 0.013 & 0.740 & -0.215 & 0.302 \\
High monthly income & -0.007 & -0.074 & 0.103 & -0.015 & 0.001 \\
Age & $\mathbf{0 . 0 2 4}$ & $\mathbf{0 . 1 7 7}$ & $<\mathbf{0 . 0 0 1}$ & $\mathbf{0 . 0 1 3}$ & $\mathbf{0 . 0 3 6}$ \\
AUDIT score & -0.005 & -0.051 & 0.218 & -0.014 & 0.003 \\
Alexithymia & $-\mathbf{0 . 0 4 1}$ & $-\mathbf{0 . 0 9 8}$ & $\mathbf{0 . 0 0 6}$ & $-\mathbf{0 . 0 7 0}$ & $-\mathbf{0 . 0 1 2}$ \\
Self esteem & $\mathbf{0 . 0 3 5}$ & $\mathbf{0 . 3 1 2}$ & $<\mathbf{0 . 0 0 1}$ & $\mathbf{0 . 0 2 4}$ & $\mathbf{0 . 0 4 6}$ \\
Depression score & $\mathbf{0 . 0 1 5}$ & $\mathbf{0 . 1 3 0}$ & $\mathbf{0 . 0 0 8}$ & $\mathbf{0 . 0 0 4}$ & $\mathbf{0 . 0 2 6}$ \\
Anxiety score & 0.002 & 0.014 & 0.740 & -0.012 & 0.017 \\
Self-esteem score & -0.002 & -0.031 & 0.413 & -0.005 & 0.002 \\
Social anxiety score & -0.002 & -0.053 & 0.167 & -0.005 & 0.001
\end{tabular}

Variables entered: Gender, marital status, socioeconomic status, age, alcohol dependence, alexithymia, depression and anxiety scales, perceived stress scale, selfesteem scale, social anxiety scale and emotional intelligence

Numbers in bold indicate significant $p$-values 
psychiatric diseases, and negatively affects mental health, particularly depression [29, 79, 80]. Previous findings from Lebanon had demonstrated the association between alcohol dependence and mental health, including depression [81], alexithymia [70, 82] and stressful living situations [83], but not suicidal ideation.

\section{Clinical implications}

Our findings support the need for clinical interventions to decrease the psychological distress linked to suicidal ideation. Additionally, the intervention on emotional intelligence might be useful to improve mental health and reduce psychological distress factors. Emotional intelligence seems to be a preventive factor that contributes to breaking the negative emotions of the person, such as depression, anxiety, and other suicide-related factors [84-86].

\section{Limitations}

Although our results are in agreement with those of previous papers, our study has some limitations. It has a cross-sectional methodology and uses self-report questionnaires as the only form of assessment, leading to a risk of reverse causality and information bias, in addition to the lack of temporality. Moreover, it did not apply external measures of suicidal ideation, behavior, or risk to test for convergent validity. Also, the sample may not be representative of the general population, as the majority of the participants were young adults, single, with a university level of education. The prevalence of suicidal ideation was relatively high and could be a biased estimate of suicidal ideation in the target population due to the lack of representativeness. Furthermore, the response to suicidal ideation questions was either yes or no, and did not assess its severity; in depth-interviews inquiring about the reasons for suicidal ideation are needed for a better evaluation. Further studies considering all these limitations are warranted to confirm our findings.

\section{Conclusion}

Our findings suggest that the Arabic version of the CSSRS subscale could serve as an appropriate assessment tool for suicidal ideation. This paper also gave insights into factors correlated with higher suicidal ideation scores, such as depression, anxiety, and alcohol dependence. Further studies are necessary to confirm our findings and implement suicide prevention programs.

\section{Abbreviations}

AUDIT: Alcohol Use Disorders Identification Test; C-SSRS: Columbia-Suicide Severity Rating Scale; HAM-A: Hamilton anxiety scale; HDRS: Hamilton depression rating scale; KMO: Kaiser-Meyer-Olkin; LSAS: Liebowitz Social Anxiety Scale; PSS: Perceived Stress Scale; RSES: Rosenberg self-esteem scale; TAS-20: Toronto Alexithymia Scale

\section{Acknowledgments}

The authors would like to thank all the participants who helped us during this project.

\section{Authors' contributions}

SO and SH designed the study; YF drafted the manuscript; SH carried out the analysis and interpreted the results; $\mathrm{RH}, \mathrm{CC}, \mathrm{MH}$ and $\mathrm{MA}$ assisted in drafting and reviewing the manuscript; $\mathrm{CC}$ and $\mathrm{MH}$ were responsible for the data collection and data entry; All authors reviewed the final manuscript and gave their consent. The author(s) read and approved the final manuscript.

\section{Funding}

None

Availability of data and materials

The authors do not have the right to share any data information as per the ethics committee rules and regulations.

Ethics approval and consent to participate

The Psychiatric Hospital of the Cross Ethics and Research Committee (HPC013-2018) approved the study protocol. Every participant gave a written consent prior to their participation in the study.

Consent for publication

Not applicable.

\section{Competing interests}

The authors have no conflicts of interest to report.

\section{Author details}

${ }^{1}$ Faculty of Science, Lebanese University, Fanar, Lebanon. ${ }^{2}$ INSERM, University Limoges, CH Esquirol, IRD, U1094 Tropical Neuroepidemiology, Institute of Epidemiology and Tropical Neurology, GEIST, Limoges, France. ${ }^{3}$ INSPECT-LB: National Institute of Public Health, Clinical Epidemiology and Toxicology, Beirut, Lebanon. ${ }^{4}$ Faculty of Arts and Sciences, Holy Spirit University of Kaslik (USEK), Jounieh, Lebanon. ${ }^{5}$ School of Pharmacy, Lebanese International University, Beirut, Lebanon. ${ }^{6}$ Research and Psychology Departments, Psychiatric Hospital of the Cross, Jall-Eddib, Lebanon. ${ }^{7}$ Faculty of Pharmacy, Lebanese University, Hadat, Lebanon. ${ }^{8}$ Faculty of Medicine, University of Nicosia, Nicosia, Cyprus. ${ }^{9}$ Faculty of Medicine and Medical Sciences, Holy Spirit University of Kaslik (USEK), Jounieh, Lebanon.

Received: 7 April 2020 Accepted: 9 February 2021

Published online: 16 February 2021

References

1. Tandon R, Nathani MK. Increasing suicide rates across Asia-a public health crisis; 2018.

2. Tøllefsen IM, Hem E, Ekeberg $\varnothing$. The reliability of suicide statistics: a systematic review. BMC Psychiatry. 2012;12(1):9.

3. World Health Organization: Preventing suicide: A global imperative. Available from: https://www.who.int/mental_health/suicide-prevention/exe summary_english.pdf?ua=1. 2014.

4. Hedegaard H, Curtin SC, Warner M. Increase in Suicide Mortality in the United States, 1999-2018. NCHS Data Brief. 2020:(362):1-8.

5. Bachmann S. Epidemiology of suicide and the psychiatric perspective. Int J Environ Res Public Health. 2018;15(7):1425.

6. Runeson B, Tidemalm D, Dahlin M, Lichtenstein P, Långström N. Method of attempted suicide as predictor of subsequent successful suicide: national long term cohort study. BMJ. 2010;341:c3222.

7. Brown GK, Beck AT, Steer RA, Grisham JR. Risk factors for suicide in psychiatric outpatients: a 20-year prospective study. J Consult Clin Psychol. 2000:68(3):371.

8. Kessler RC, Borges G, Walters EE. Prevalence of and risk factors for lifetime suicide attempts in the National Comorbidity Survey. Arch Gen Psychiatry. 1999:56(7):617-26.

9. Langlois S, Morrison P. Suicide deaths and suicide attempts. Health Rep. 2002;13(2):9-22.

10. World Health Organization: Suicide data. Available from: https://www.who. int/mental_health/prevention/suicide/suicideprevent/en/. [Accessed 30 Jan 2020]. 2020 
11. Cohen LJ, Ardalan F, Yaseen Y, Galynker I. Suicide Crisis Syndrome Mediates the Relationship Between Long-term Risk Factors and Lifetime Suicidal Phenomena. Suicide Life Threat Behav. 2018;48(5):613-23.

12. Fawcett J, Scheftner WA, Fogg L, Clark DC, Young MA. Time-related predictors of suicide in major affective disorder. Am J Psychiatr. 1990;147(9): 1189-94.

13. Rogers ML, Chiurliza B, Hagan CR, Tzoneva M, Hames JL, Michaels MS, Hitschfeld MJ, Palmer BA, Lineberry TW, Jobes DA, et al. Acute suicidal affective disturbance: factorial structure and initial validation across psychiatric outpatient and inpatient samples. J Affect Disord. 2017;211:1-11.

14. Freudenreich O. Depression and suicide. In: Psychotic Disorders. New York: Springer; 2020. p. 399-409.

15. Meine IR, Cheiram MC, Jaeger FP. Depression and suicide: the adolescent facing sociocultural risk factors. Res Soc Dev. 2019;8(12):448121882.

16. Foley DL, Goldston DB, Costello EJ, Angold A. Proximal psychiatric risk factors for suicidality in youth: the Great Smoky Mountains study. Arch Gen Psychiatry. 2006;63(9):1017-24.

17. Placidi GP, Oquendo MA, Malone KM, Brodsky B, Ellis SP, Mann JJ. Anxiety in major depression: relationship to suicide attempts. Am J Psychiatr. 2000; 157(10):1614-8.

18. Kaplan MS, McFarland BH, Huguet N, Newsom JT. Physical illness, functional limitations, and suicide risk: A population-based study. Am J Orthopsychiatry. 2007;77(1):56-60.

19. Gallagher M, Prinstein MJ, Simon V, Spirito A. Social anxiety symptoms and suicidal ideation in a clinical sample of early adolescents: examining loneliness and social support as longitudinal mediators. J Abnorm Child Psychol. 2014;42(6):871-83.

20. Katz C, Yaseen ZS, Mojtabai R, Cohen LJ, Galynker II. Panic as an independent risk factor for suicide attempt in depressive illness: findings from the National Epidemiological Survey on alcohol and related conditions (NESARC). J Clin Psychiatry. 2011;72(12):1628-35.

21. Wang Y, Sareen J, Afifi TO, Bolton SL, Johnson EA, Bolton JM. Recent stressful life events and suicide attempt. Psychiatr Ann. 2012;42(3):101-8.

22. Selaman ZM, Chartrand HK, Bolton JM, Sareen J. Which symptoms of posttraumatic stress disorder are associated with suicide attempts? J Anxiety Disord. 2014;28(2):246-51.

23. Rosiek A, Rosiek-Kryszewska A, Leksowski Ł, Leksowski K. Chronic stress and suicidal thinking among medical students. Int J Environ Res Public Health. 2016;13(2):212

24. Nguyen DT, Wright EP, Dedding C, Pham TT, Bunders J. Low self-esteem and its association with anxiety, depression, and suicidal ideation in Vietnamese secondary school students: a cross-sectional study. Front Psychiatry. 2019;10:698.

25. Wilburn VR, Smith DE. Stress, self-esteem, and suicidal ideation in late adolescents. Adolescence. 2005;40(157):33-45.

26. Wild LG, Flisher AJ, Lombard C. Suicidal ideation and attempts in adolescents: associations with depression and six domains of self-esteem. J Adolesc. 2004;27(6):611-24

27. Overholser JC, Adams DM, Lehnert KL, Brinkman DC. Self-esteem deficits and suicidal tendencies among adolescents. J Am Acad Child Adolesc Psychiatry. 1995;34(7):919-28.

28. Lamis DA, Malone PS. Alcohol use and suicidal behaviors among adults: A synthesis and theoretical model. Suicidol Online. 2012;3:4

29. Pompili M, Serafini G, Innamorati M, Dominici G, Ferracuti S, Kotzalidis GD, Serra G, Girardi P, Janiri L, Tatarelli R. Suicidal behavior and alcohol abuse. Int J Environ Res Public Health. 2010;7(4):1392-431.

30. Sifneos PE. The prevalence of 'alexithymic'characteristics in psychosomatic patients. Psychother Psychosom. 1973;22(2-6):255-62.

31. Hemming L, Taylor P, Haddock G, Shaw J, Pratt D. A systematic review and meta-analysis of the association between alexithymia and suicide ideation and behaviour. J Affect Disord. 2019;254:34-48.

32. Foran $\mathrm{HM}, \mathrm{O}$ 'Leary KD. The role of relationships in understanding the alexithymia-depression link. Eur J Personal. 2013;27(5):470-80

33. Zeidner M, Matthews G, Roberts RD. The emotional intelligence, health, and well-being nexus: what have we learned and what have we missed? Appl Psychol Health Well-Being. 2012;4(1):1-30.

34. Lopes PN, Salovey P, Côté S, Beers M, Petty RE. Emotion regulation abilities and the quality of social interaction. Emotion. 2005;5(1):113.

35. Domínguez-García E, Fernández-Berrocal P. The association between emotional intelligence and suicidal behavior: a systematic review. Front Psychol. 2018;9:2380
36. Bou Khalil R. The psychological wellbeing of the Lebanese society lies between incremental suicide rates and financial stress. Asian J Psychiatr. 2019;42:85-6.

37. Alonso J, Angermeyer MC, Bernert S, Bruffaerts R, Brugha TS, Bryson H, de Girolamo G, Graaf R, Demyttenaere K, Gasquet I, et al. Prevalence of mental disorders in Europe: results from the European study of the epidemiology of mental disorders (ESEMeD) project. Acta Pschychiatr Scand Suppl. 2004; 109(s420):21-7.

38. Karam EG, Mneimneh ZN, Dimassi H, Fayyad JA, Karam AN, Nasser SC, Chatterji S, Kessler RC. Lifetime prevalence of mental disorders in Lebanon: first onset, treatment, and exposure to war. PLoS Med. 2008;5(4):e61.

39. Cherri Z, Arcos González P, Castro Delgado R. The Lebanese-Syrian crisis: impact of influx of Syrian refugees to an already weak state. Risk Manag Healthc Policy. 2016;9:165-72.

40. Obeid S, Haddad C, Salame W, Kheir N, Hallit S. Xenophobic attitudes, behaviors and coping strategies among Lebanese people toward immigrants and refugees. Perspect Psychiatr Care. 2019;55(4):710-7.

41. Chahine M, Salameh P, Haddad C, Sacre H, Soufia M, Akel M, Obeid S, Hallit $\mathrm{R}$, Hallit S. Suicidal ideation among Lebanese adolescents: scale validation, prevalence and correlates. BMC Psychiatry. 2020;20(1):304.

42. Eskin M, AlBuhairan F, Rezaeian M, Abdel-Khalek AM, Harlak H, El-Nayal M, Asad N, Khan A, Mechri A, Noor IM, et al. Suicidal thoughts, attempts and motives Among University students in 12 Muslim-majority countries. Psychiatr Q. 2019;90(1):229-48.

43. Gabrielle Macaron MF, Matar D, Bou-Khalil R, Kazour F, Nehme-Chlela D, Richa S. Anxiety, Depression and Suicidal Ideation in Lebanese Patients Undergoing Hemodialysis. Community Ment Health J. 2014;50:235-8.

44. Mahfoud ZR, Afifi RA, Haddad PH, DeJong J. Prevalence and determinants of suicide ideation among Lebanese adolescents: results of the GSHS Lebanon 2005. J Adolesc. 2011;34(2):379-84.

45. Chen PC, Lee LK, Wong KC, Kaur J. Factors relating to adolescent suicidal behavior: a cross-sectional Malaysian school survey. J Adolescent Health. 2005;37(4):337. e311-6.

46. Fochtmann $\sqcup$, Jacobs DG. Suicide risk assessment and management in practice: the quintessential clinical activity. Acad Psychiatry. 2015;39(4):490-1.

47. Runeson B, Odeberg J, Pettersson A, Edbom T, Jildevik Adamsson I, Waern M. Instruments for the assessment of suicide risk: a systematic review evaluating the certainty of the evidence. PLoS One. 2017;12(7):e0180292.

48. Posner K, Brown GK, Stanley B, Brent DA, Yershova KV, Oquendo MA, Currier GW, Melvin GA, Greenhill L, Shen S. The Columbia-suicide severity rating scale: initial validity and internal consistency findings from three multisite studies with adolescents and adults. Am J Psychiatr. 2011;168(12):1266-77.

49. Lahoud N, Zakhour M, Haddad C, Salameh P, Akel M, Fares K, Hallit S, Obeid S. Burnout and its relationships with alexithymia, stress, self-esteem, depression, alcohol use disorders, and emotional intelligence: results from a Lebanese cross-sectional study. J Nerv Ment Dis. 2019;207(8):642-50.

50. Obeid S, Haddad C, Akel M, Fares K, Salameh P, Hallit S. Factors associated with the adults' attachment styles in Lebanon: the role of alexithymia, depression, anxiety, stress, burnout, and emotional intelligence. Perspect Psychiatr Care. 2019;55(4):607-17.

51. Obeid S, Haddad C, Zakhour M, Fares K, Akel M, Salameh P, Hallit S. Correlates of self-esteem among the Lebanese population: A cross-sectional study. Psychiatr Danub. 2019;31(4):429-39.

52. Obeid S, Lahoud N, Haddad C, Sacre H, Fares K, Akel M, Salameh P, Hallit S. Factors associated with anxiety among the Lebanese population: the role of alexithymia, self-esteem, alcohol use disorders, emotional intelligence and stress and burnout. Int J Psychiatry Clin Pract. 2020;24(2):151-62.

53. Comrey AL, Lee HB. A first course in factor analysis: psychology press; 2013.

54. Obeid S, Hallit CAE, Haddad C, Hany Z, Hallit S. Validation of the Hamilton depression rating scale (HDRS) and sociodemographic factors associated with Lebanese depressed patients. L'Encéphale. 2018;44(5):397-402.

55. Hallit S, Haddad C, Hallit R, Akel M, Obeid S, Haddad G, Soufia M, Khansa W, Khoury R, Kheir N. Validation of the Hamilton anxiety rating scale and state trait anxiety inventory $\mathrm{a}$ and $\mathrm{B}$ in Arabic among the Lebanese population. Clin Epidemiol Global Health. 2020;8(4):1104-9.

56. Nilsson ME, Suryawanshi S, Gassmann-Mayer C, Dubrava S, McSorley P, Jiang K. Columbia-suicide severity rating scale scoring and data analysis guide. CSSRS Scoring. 2013;2:1-13.

57. World Health Organization. AUDIT: the Alcohol Use Disorders Identification Test : guidelines for use in primary health care / Thomas F. Babor ... [ et al.] 
2nd ed. World Health Organization; 2001. https://apps.who.int/iris/handle/ 0665/67205

58. Bagby RM, Parker JD, Taylor GJ. The twenty-item Toronto alexithymia scale-l. item selection and cross-validation of the factor structure. J Psychosom Res. 1994;38(1):23-32.

59. Rosenberg M. Society and the adolescent self-image: Princeton university press; 2015.

60. Hamilton M. The Hamilton rating scale for depression. In: Assessment of depression. New York: Springer; 1986. p. 143-52.

61. Hamilton M. The assessment of anxiety states by rating. $\mathrm{Br} J$ Med Psychol. 1959;32(1):50-5

62. Cohen S, Kamarck T, Mermelstein R. Perceived stress scale. Meas Stress. 1994;10:1-2.

63. Liebowitz MR. Pharmacopsychiatry MP: Social phobia; 1987.

64. Mohapel P. The quick emotional intelligence self-assessment. San Diego City College MESA Program Paul mohapel@ shaw ca; 2015.

65. Marsh HW, Hau K-T, Wen Z. In search of golden rules: comment on hypothesis-testing approaches to setting cutoff values for fit indexes and dangers in overgeneralizing Hu and Bentler's (1999) findings. Struct Equ Model. 2004;11(3):320-41.

66. Taber KS. The use of Cronbach's alpha when developing and reporting research instruments in science education. Res Sci Educ. 2018;48(6):1273-96.

67. Ratner B. The correlation coefficient: Definition. DM Stat-1. 2013:49:50

68. Serrani Azcurra D. Psychometric validation of the Columbia-suicide severity rating scale in Spanish-speaking adolescents. Colombia Med. 2017:48(4): $174-82$

69. Khansa W, Haddad C, Hallit R, Akel M, Obeid S, Haddad G, Soufia M, Kheir N, Abi Elias Hallit C, Khoury R. Interaction between anxiety and depression on suicidal ideation, quality of life, and work productivity impairment: results from a representative sample of the Lebanese population. Perspect Psychiatr Care. 2020;56(2):270-279. https://doi.org/10.1111/ppc.12423.

70. Obeid S, Akel M, Haddad C, Fares K, Sacre H, Salameh P, Hallit S. Factors associated with alexithymia among the Lebanese population: results of a cross-sectional study. BMC Psychology. 2019;7(1):80.

71. Bentley KH, Franklin JC, Ribeiro JD, Kleiman EM, Fox KR, Nock MK. Anxiety and its disorders as risk factors for suicidal thoughts and behaviors: A metaanalytic review. Clin Psychol Rev. 2016;43:30-46.

72. Takeuchi T, Nakao M. The relationship between suicidal ideation and symptoms of depression in Japanese workers: a cross-sectional study. BMJ Open. 2013:3(11):e003643.

73. Norton PJ, Temple SR, Pettit JW. Suicidal ideation and anxiety disorders: elevated risk or artifact of comorbid depression? I Behav Ther Exp Psychiatry. 2008;39(4):515-25.

74. Weissman MM, Bland RC, Canino GJ, Greenwald S, Hwu HG, Joyce PR Karam EG, Lee CK, Lellouch J, Lepine JP, et al. Prevalence of suicide ideation and suicide attempts in nine countries. Psychol Med. 1999;29(1):9-17.

75. Shediac-Rizkallah MC, Soweid RAA, Farhat TM, Yeretzian J. Adolescent health-related behaviors in postwar Lebanon: findings among students at the American University of Beirut. Int Q Commun Health Educ. 2000;20(2): 115-31.

76. Izadinia N, Amiri M, Jahromi RG, Hamidi S. A study of relationship between suicidal ideas, depression, anxiety, resiliency, daily stresses and mental health among Tehran university students. I. Soc Behav Sci. 2010;5:1615-9.

77. Wu SY, Zhao HJ. The relationship between life stress, depression and suicide ideation among undergraduates. Modern Prev Med. 2009;36:2918-9.

78. Robins E, Murphy GE, Wilkinson RH Jr, Gassner S, Kayes J. Some clinical considerations in the prevention of suicide based on a study of 134 successful suicides. Am J Public Health Nation's Health. 1959;49(7):888-99.

79. Darvishi N, Farhadi M, Haghtalab T, Poorolajal J. Alcohol-related risk of suicidal ideation, suicide attempt, and completed suicide: a meta-analysis. PLoS One. 2015:10(5):e0126870

80. Kumar S, Kuchhal A, Dixit V, Jaiswal S: Suicidal ideation and its correlates in patients of alcohol dependence syndrome. Int J Contemp Med Res. 2016; 3(5):1392-7.

81. Obeid S, Lahoud N, Haddad C, Sacre H, Akel M, Fares K, Salameh P, Hallit S. Factors associated with depression among the Lebanese population: results of a cross-sectional study. Perspect Psychiatr Care. 2020;56(4):956-67.

82. Zakhour M, Haddad C, Salameh P, Akel M, Fares K, Sacre H, Hallit S, Obeid S. Impact of the interaction between alexithymia and the adult attachment styles in participants with alcohol use disorder. Alcohol. 2020;83:1-8.
83. Obeid S, Akel M, Haddad C, Fares K, Sacre H, Salameh P, Hallit S. Factors associated with alcohol use disorder: the role of depression, anxiety, stress, alexithymia and work fatigue- a population study in Lebanon. BMC Public Health. 2020;20(1):245.

84. Abdollahi A, Hosseinian S, Rasuli R. Emotional intelligence moderates Anhedonia and suicidal ideation in depressed patients. Psychol Rep. 2020; 123(3):660-73.

85. Fedina L, Nam B, Jun H-J, Shah R, Von Mach T, Bright CL, DeVylder J. Moderating effects of resilience on depression, psychological distress, and suicidal ideation associated with interpersonal violence. J Interpers Violence. 2017:886260517746183. https://doi.org/10.1177/0886260517746183.

86. Mérida-López S, Extremera N, Rey L. Understanding the links between selfreport emotional intelligence and suicide risk: does psychological distress mediate this relationship across time and samples? Front Psychiatry. 2018;9; 184

\section{Publisher's Note}

Springer Nature remains neutral with regard to jurisdictional claims in published maps and institutional affiliations.
Ready to submit your research? Choose BMC and benefit from:

- fast, convenient online submission

- thorough peer review by experienced researchers in your field

- rapid publication on acceptance

- support for research data, including large and complex data types

- gold Open Access which fosters wider collaboration and increased citations

- maximum visibility for your research: over $100 \mathrm{M}$ website views per year

At BMC, research is always in progress.

Learn more biomedcentral.com/submissions 